\title{
Caracterização físico-química de cinza de osso bovino para avaliação do seu potencial uso agrícola ${ }^{1}$
}

\author{
Eduardo Pacca Luna Mattar², Elízio Ferreira Frade Júnior ${ }^{2}$, Eliane de Oliveira²
}

\begin{abstract}
Physical-chemical characterization of bovine bone ash for evaluating its potential agricultural use

The manufacturing of bovine bone ash is a low cost and easy production process which can be adopted for making good use of animal residues, in locations without infrastructure, such as the family production units. This study aimed at describing the manufacturing process of bone ash and characterizing the physical and chemical parameters of the resulting material for organic fertilization. The experiment was performed with three replications, being evaluated the bovine bone ash manufacturing process yield, as well as its density, water retention capacity, $\mathrm{pH}$ of the resulting material after burning and contents of total calcium, calcium soluble in water, total phosphorus and phosphorus soluble in citric acid and in ammonium citrate. The process resulted in an average yield of $24.4 \%$ and the bovine bone ash presented $33.07 \%$ of total calcium, $15.6 \%$ of total phosphorus, $10.4 \%$ of phosphorus soluble in citric acid, $\mathrm{pH}$ of 9.94 , density of $0.89 \mathrm{~g} \mathrm{~cm}^{-3}$ and water retention capacity of $73.3 \%$. The bovine bone ash showed promising characteristics, with potential for being used as source of phosphorus and calcium in the organic fertilization process.
\end{abstract}

KEY-WORDS: Animal residue; organic agriculture; fertilization.

\section{INTRODUÇÃO}

As empresas de carnes e derivados e as graxarias são caracterizadas pelo alto consumo de água e energia, além da geração de efluentes com carga poluidora (Pacheco 2006). As impurezas são, principalmente, orgânicas e putrescíveis, com decomposição rápida e formação de gases mal odorantes (Pacheco \& Wolff 2004, Pacheco 2006, Dim et al. 2010), situação que é agravada para as comunidades situadas próximas aos estabelecimentos, considerando-se que os depósitos encontram-se a céu aberto (Dim et al. 2010).

\section{RESUMO}

A fabricação de cinza de osso bovino é um processo de baixo custo e fácil execução, que pode ser adotado para o aproveitamento de resíduos animais, em locais com indisponibilidade de infraestrutura, como as unidades de produção familiar. Este estudo objetivou descrever o processo de fabricação de cinza de osso e caracterizar parâmetros físicos e químicos do material resultante, para fins de adubação orgânica. Foi realizado experimento com três repetições, no qual foi avaliado o rendimento do processo de fabricação da cinza de osso bovino, bem como a densidade, capacidade de retenção de água, pH do material resultante após a queima e teores de cálcio total, cálcio solúvel em água, fósforo total e fósforo solúvel em ácido cítrico e em citrato de amônio. O processo obteve rendimento médio de $24,4 \%$ e a cinza de osso bovino apresentou $33,07 \%$ de teor de cálcio total, $15,6 \%$ de fósforo total, $10,4 \%$ de fósforo solúvel em ácido cítrico, $\mathrm{pH}$ de 9,94, densidade de $0,89 \mathrm{~g} \mathrm{~cm}^{-3}$ e capacidade de retenção de água de $73,3 \%$. A cinza de osso bovino apresentou características promissoras, tendo potencial para servir como fonte de fósforo e cálcio, para uso na adubação orgânica.

PALAVRAS-CHAVE: Resíduo animal; agricultura orgânica; adubação.

Animais mortos e carcaças oferecem risco à saúde humana e animal e devem ser processados por estabelecimentos inspecionados e autorizados pela vigilância sanitária, para garantir o processo que leve o resíduo à esterilização, com consequente destruição dos patógenos (Pacheco 2006).

O processamento e a destinação dos subprodutos do abate dependem de características locais, como a existência de mercado e logística entre operações (Pacheco \& Yamanaka 2006). Em cidades com abatedouros de pequeno porte, e que não possuem infraestrutura para graxaria, os resíduos sólidos são destinados a lixões ou aterros e descartados sem 
controle sanitário, sendo misturados ao lixo comum. Desta forma, agravam os problemas ambientais e de saúde pública, resultando em grande desperdício, quando se pensa em reciclagem agrícola.

Resíduos sólidos processados, devido à natureza química dos mesmos, podem servir como fontes de nutrientes essenciais para as plantas. Costa et al. (2009) descrevem o tratamento biológico por meio da compostagem, para reaproveitamento de resíduos sólidos em pequenos frigoríficos e abatedouros. Malavolta et al. (2002) mencionam o uso de farinha de ossos crus, autoclavados e degelatinados, como adubos fosfatados de primeira ordem.

Os ossos são constituídos, predominantemente, por hidroxiapatita, que pode se decompor, sob a ação do calor, em $\beta$-fosfato tricálcico, $\mathrm{CaO}$ e água (Tsuyoshi et al. 1999). Além da presença de cálcio e fósforo, os ossos apresentam pequenas quantidades de outros íons, em sua composição, como o sódio e o potássio, e, dependendo da lavagem, Fe proveniente do sangue (Miyahara et al. 2007).

Em relação ao uso na agricultura, registros históricos mostram que ossos foram os primeiros fertilizantes fosfatados e amplamente utilizados na Europa, durante o Século XIX (UNIDO 1998). John (1840) relatou que, no Século XVIII, agricultores de Sheffield e Yorkshire (Inglaterra) utilizaram, na agricultura, ossos moídos descartados por torneiros de ossos e marfim. Quando a oferta de ossos de animais diminuiu, na Europa, ossos humanos foram recolhidos de campos de batalha ou cemitérios, para uso na agricultura, e, por volta de 1830 , o tratamento de ossos com ácido sulfúrico era uma prática comum (UNIDO 1998).

A Typographia Commercial Portuense (1839) descreveu o benefício do uso de ossos moídos na agricultura do Século XIX, abordando a importação e exportação de ossos moídos, em Portugal, e as tecnologias existentes na época, incluindo o maquinário utilizado para moagem, a qualidade do material, os cuidados no armazenamento e orientações de uso em campo.

Segundo Albuquerque (1996), existem registros de que, no Século XIX, a Inglaterra importou esqueletos humanos de guerras napoleônicas e de antigos cemitérios, para uso agrícola, e de que franceses já conheciam a eficiência de ossos de animais calcinados, como adubos para olerícolas. Mazoyer \& Roudart (1933) relataram que, no final do Século XIX, iniciou-se, na Europa, a exploração e o uso de materiais fosfatados como adubo, incluindo a utilização de ossos bovinos.

Atualmente, como alternativa para a adubação fosfatada e calcinada, utilizam-se farinhas de ossos resultantes do reaproveitamento de carcaças de bovinos e suínos. Caione et al. (2011) descreveram desempenho satisfatório da farinha de osso, como adubo fosfatado para cana-de-açúcar, e Rodrigues et al. (2009) mencionaram seu uso como componente de biofertilizantes.

O processo de fabricação da farinha de osso exige a etapa de cozimento com digestores (que podem ser substituídos por "panelões", para quantidades menores de matéria-prima) ou autoclaves, e posterior percolação com aquecimento a vapor (Pacheco 2006). O elevado custo energético do processamento dificulta o reaproveitamento de carcaças de animais que, em locais sem infraestrutura para graxaria, são descartadas sem adequação às normas ambientais $\mathrm{e}$ fiscalização do setor público.

Uma alternativa de baixo custo, fácil execução e que pode ser realizada na ausência de infraestrutura para graxaria é a produção de cinza de ossos a partir de carcaças de bovinos provenientes de abatedouros e açougues, expostas à queima. Trata-se de uma tecnologia barata e acessível para produtores rurais, que poderia diminuir o desperdício de materiais, com potencial reaproveitamento agrícola.

Sob este enfoque, o presente estudo objetivou descrever e avaliar o rendimento do processo de fabricação da cinza de osso, a partir da queima padrão, e, principalmente, caracterizar parâmetros físicos e químicos do material resultante, podendo subsidiar, posteriormente, testes para sua utilização como fertilizante agrícola.

\section{MATERIAL E MÉTODOS}

O trabalho foi realizado entre janeiro e junho de 2012 e iniciou-se a partir da coleta de resíduos de ossos bovinos, em açougue localizado em Cruzeiro do Sul, extremo oeste do Estado do Acre. Os ossos foram acondicionados e transportados em barril de plástico de $200 \mathrm{~L}$, com tampa de rosca removível, para facilitar o transporte e proporcionar melhor higiene do material. As quantidades de resíduos coletados não foram uniformes, pois dependeram da oferta diária do açougue. Após cada coleta, procedeu-se à aferição do peso dos resíduos de osso bovino, em balança de precisão analítica. 
Em seguida à pesagem, os ossos bovinos foram queimados em churrasqueira de alvenaria (dimensões internas de 98,0 cm de largura x 70,0 cm de comprimento x 90,0 cm de altura). Durante o processo, utilizou-se carvão vegetal, com o objetivo de se obter padronização nos processos, sendo os ossos acumulados em duas caixas retangulares de estrutura de metal e sem fundo, confeccionadas em tela moeda $(53,0 \mathrm{~cm}$ de comprimento x $28,0 \mathrm{~cm}$ de altura $\mathrm{x} 23,0 \mathrm{~cm}$ de largura), as quais foram utilizadas para evitar a mistura da cinza de osso com a cinza do carvão. Dentro da churrasqueira, foram inseridas duas grades de tela moeda, para acomodação do carvão e dos ossos bovinos. As grades foram dispostas no interior da churrasqueira, separadas $15,0 \mathrm{~cm}$ uma da outra e afastadas $15,0 \mathrm{~cm}$ das paredes da churrasqueira, de modo que todas as faces das grades estivessem com espaço suficiente para ser preenchido com carvão (Figura 1), visando a uniformizar o material resultante.

As queimas foram iniciadas no final da tarde e os ossos coletados na manhã do dia seguinte, após resfriamento, quando a cinza de osso apresentou coloração esbranquiçada (Figura 2). O material foi retirado da churrasqueira com espátula de alumínio, sendo pesado em balança analítica, moído em triturador elétrico (Yamaha/Motor 15) e, finalmente, tamisado em peneira de $2 \mathrm{~mm}$ de abertura de malha, para obtenção de material homogêneo. Foram realizadas três repetições do processo de fabricação de cinza de osso, sendo que, para cada processo, foi obtida uma amostra.

O rendimento, em percentagem, do processo foi calculado a partir da fórmula Rendimento do processo $=($ MI X 100) $/$ MF, em que MI $=$ média da massa inicial, que consiste no total da massa de resíduos de ossos bovinos, e MF = média da massa final, que consiste no total de massa das cinzas de ossos, após a queima.

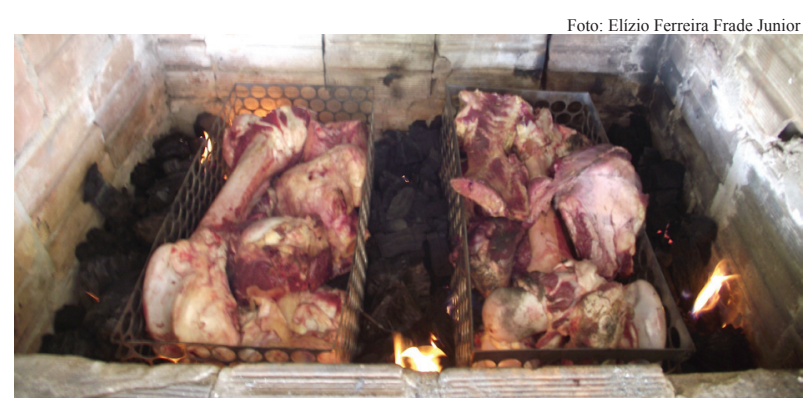

Figura 1. Ossos bovinos descartados e preparados para queima, em churrasqueira com grade de tela moeda (Cruzeiro do Sul, AC, 2012).

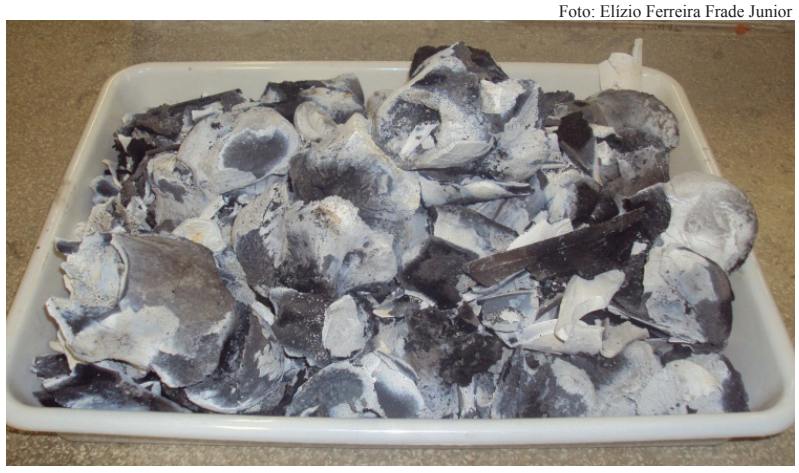

Figura 2. Ossos bovinos após o processo de incineração (Cruzeiro do Sul, AC, 2012).

Para cada amostra de cinza de osso bovino triturada e homogeneizada, procedeu-se à caracterização física e química. Os parâmetros $\mathrm{pH}$ em $\mathrm{H}_{2} \mathrm{O}$, relação da suspensão solo : água de 1:2,5 e densidade foram calculados segundo Embrapa (1997). Os teores de cálcio total, cálcio solúvel em água, fósforo total, fósforo solúvel em ácido cítrico e fósforo solúvel em citrato de amônio foram aferidos segundo metodologia proposta por Brasil (2007b). A caracterização física de densidade e capacidade de retenção de água, assim como o cálculo utilizado, foram determinados segundo Melo et al. (1998).

\section{RESULTADOS E DISCUSSÃO}

A Tabela 1 ilustra a massa inicial, massa após a queima e rendimento médio do processo de fabricação da cinza de ossos, a partir de ossos bovinos, por meio de queima padrão, com utilização de carvão vegetal como combustível. O rendimento médio foi de $24,4 \%$ e o coeficiente de variação de $3,1 \%$, provavelmente relacionado à pequena variabilidade nos teores de água e outros compostos constituintes, encontrados associados aos tecidos ósseos, de forma geral, o que contribui para a estabilidade do rendimento médio, independentemente da origem do material a ser utilizado.

Miyahara et al. (2007) obtiveram, aproximadamente, $60 \%$ de rendimento mássico, na queima de ossos in natura, ou seja, $40 \%$ da massa dos ossos compunham-se de material orgânico que foi eliminado durante o aquecimento. $\mathrm{O}$ maior rendimento observado, provavelmente, deveu-se à metodologia adotada, a qual incluiu pré-tratamento de autoclavagem e secagem do material a $100^{\circ} \mathrm{C}$, para remoção 
Tabela 1. Densidade, capacidade máxima de retenção de água e rendimento, após a queima de ossos bovinos (Cruzeiro do Sul, AC, 2012).

\begin{tabular}{lcccc}
\hline \multicolumn{1}{c}{ Variável } & Unidade & Média (3 repetições) & Intervalo de confiança & C.V. \\
\hline Densidade & $\mathrm{g} \mathrm{cm}^{-3}$ & 0,89 & 0,14 & 7,3 \\
Capacidade máxima de retenção de água & $\%$ & 73,30 & 9,17 & 7,4 \\
Rendimento após a queima & $\%$ & 24,40 & 2,04 & 3,1 \\
\hline
\end{tabular}

de gorduras e outros tecidos animais, antes da calcinação, o que deve ter contribuído para a evaporação da água associada ao material.

A partir de $100^{\circ} \mathrm{C}$, começou a haver diminuição na quantidade de massa do material ósseo. Isto ocorreu devido à perda na forma de vapor da água que estava adsorvida na superfície e nos poros abertos do material (Miyahara et al. 2007, Ferreira et al. 2009).

A Análise Térmica Diferencial, até a temperatura de $1.200^{\circ} \mathrm{C}$, com aquecimento do material in natura em uma mufla, demonstrou que, na faixa de temperatura de $300-700^{\circ} \mathrm{C}$, houve queda acentuada da massa, devida, provavelmente, à reação de combustão da matéria orgânica e reações exotérmicas (Miyahara et al. 2007, Ferreira et al. 2009). Comparativamente ao processo de fabricação da farinha de osso, o ponto negativo, na produção da cinza de osso, é, justamente, a perda do carbono, durante o processo de combustão, que, consequentemente, também leva a um menor rendimento do processo.

A densidade média da cinza de ossos foi de $0,89 \mathrm{~g} \mathrm{~cm}^{-3}$, valor muito inferior ao encontrado por Gouvêa et al. (2007): 2,51-2,91 $\mathrm{g} \mathrm{cm}^{-3}$, de acordo com a variação da temperatura de $700-1.000^{\circ} \mathrm{C}$ de calcinação realizada em mufla. As cinzas analisadas por estes autores receberam tratamento diferente, em relação à forma de queima (com temperatura controlada em mufla), e, também, em relação à moagem do produto, realizada em almofariz de ágata e, em seguida, em moinho de bolas com jarro e elementos de porcelana, por 24 horas.

Segundo Miyahara et al. (2007), quando o material é calcinado a $450^{\circ} \mathrm{C}$, temperatura em que a matéria orgânica é pirolizada, ocorre a formação de uma camada de carvão nos ossos, que é eliminada sob temperaturas superiores.

Os ossos bovinos apresentaram coloração variando entre branco e cinza escuro (Figura 2), o que sugere a presença de carbono residual, o qual não foi totalmente eliminado. Miyahara et al. (2007) observaram que o material calcinado à temperatura da pirólize do carbono orgânico $\left(450^{\circ} \mathrm{C}\right)$ apresentou coloração negra. Estes mesmos autores constataram que temperaturas superiores a $500^{\circ} \mathrm{C}$ são suficientes para completar a queima do carbono residual, ao mesmo tempo em que o material torna-se branco.

Não foram encontradas relações entre as variações de cor observadas em ossos calcinados a $1.000^{\circ} \mathrm{C}$ e diferenças na fase cristalina do material ou na composição química relacionada ao fósforo, que se mantém na forma de hidroxiapatita (Miyahara et al. 2007).

Com relação às propriedades químicas, o material resultante apresentou $\mathrm{pH}$ médio de 9,94, teor médio de $\mathrm{Ca}_{\text {total }}$ de $33,07 \%$, teor médio de $\mathrm{P}_{\text {total }}$ de $15,64 \%$ e teor médio de $\mathrm{P}$ solúvel em ácido cítrico de $10,44 \%$. Considerando-se o valor de conversão de 2,29 (Malavolta 1989), a quantidade de $\mathrm{P}_{2} \mathrm{O}_{5}$ total encontrada foi de $35,81 \%$. A Tabela 2 discrimina os valores obtidos para cada uma das amostras. A análise química realizada por fluorescência de raio $\mathrm{X}$, em cinza de ossos bovinos calcinados a $1.000^{\circ} \mathrm{C}$, com distribuição granulométrica abaixo de $10 \mu \mathrm{m}$, resultou em teor total de $\mathrm{P}_{2} \mathrm{O}_{5}$ de 41,7-42,6\%, ou $18,2-18,6 \%$ de $\mathrm{P}_{\text {total }}$, e de $\mathrm{CaO}$ de $55,0-55,6 \%$, ou $39,3-39,7 \%$ de $\mathrm{Ca}_{\text {total }}$ (Miyahara et al. 2007).

A concentração de $\mathrm{P}_{2} \mathrm{O}_{5}$ total e $\mathrm{P}_{2} \mathrm{O}_{5}$ solúvel em ácido cítrico da cinza de osso bovino, comparativamente aos fertilizantes fosfatados incluídos na legislação brasileira (Brasil 2007a), foi satisfatória. Dos 41 adubos fosfatados, 27 apresentam menor concentração de $\mathrm{P}_{2} \mathrm{O}_{5}$ total, dentre eles o fosfato natural reativo, farinha de osso calcinado, fosfato natural, farinha de osso autoclavado, superfosfato duplo, superfosfato simples e termofosfato magnesiano. Dos 12 adubos com $\mathrm{P}_{2} \mathrm{O}_{5}$ solúvel em ácido cítrico, somente o fosfato natural reativo apresentou percentagem superior à da cinza de osso bovino.

Ainda considerando-se a concentração mínima exigida pela legislação brasileira, para os fertilizantes minerais simples (Brasil 2007a), com relação ao teor de $\mathrm{Ca}^{2+}$ total, dos 40 fertilizantes calcinados utilizados na agricultura, a cinza de osso bovino somente apresentou percentagem inferior à do hidróxido de cálcio e óxido de cálcio. 
Tabela 2. Análise de fósforo e cálcio solúvel, total e pH de cinza de ossos bovinos (Cruzeiro do Sul, AC, 2012).

\begin{tabular}{lcccc}
\hline \multicolumn{1}{c}{ Variável } & Unidade & Média (3 repetições) & Intervalo de confiança & C.V. \\
\hline Fósforo & & & & \\
Solúvel em água & $\mathrm{mg} \mathrm{kg}^{-1}$ & 147,00 & 233,00 & 76,45 \\
Solúvel em citrato de amônio & $\%$ & 5,53 & 1,65 & 14,48 \\
Solúvel em ácido cítrico & $\%$ & 10,44 & 2,48 & 11,49 \\
Total & $\%$ & 15,64 & 1,44 & 4,47 \\
\hline Cálcio & & & & \\
Solúvel em água & $\mathrm{mg} \mathrm{kg}^{-1}$ & 212,51 & 190,00 & 43,44 \\
Total & $\%$ & 33,07 & 2,06 & 3,02 \\
\hline $\mathrm{pH}$ & $\mathrm{H}_{2} \mathrm{O}(1: 2,5)$ & 9,94 & 0,65 & 3,15 \\
\hline
\end{tabular}

A cinza de osso apresentou $35,81 \%$ de $\mathrm{P}_{2} \mathrm{O}_{5}$ total e $23,94 \%$ de $\mathrm{P}_{2} \mathrm{O}_{5}$ solúvel em ácido cítrico, com $33,07 \%$ de cálcio. Comparativamente, o termofosfato magnesiano, fonte de fósforo de uso rotineiro na agricultura orgânica, apresentou $17 \%$ de $\mathrm{P}_{2} \mathrm{O}_{5}$ total e mínimo de $11 \%$ de $\mathrm{P}_{2} \mathrm{O}_{5}$ solúvel em ácido cítrico, com $20 \%$ de cálcio (Brasil 2007a).

Para o processo de fabricação de cinza de osso, não se recomenda a utilização de carvão vegetal, uma vez que o resíduo de osso bovino é um material de fácil combustão, devido à presença de gordura na composição, que pode chegar a 12\% (IPTS 2005). Sob este enfoque, a lenha da própria unidade de produção pode ser utilizada, diminuindo o custo de produção do processamento. Por se tratar de uma queima padrão, o processo de fabricação de cinza de osso apresenta rendimento satisfatório (pouco menos de $25 \%$ ).

O material resultante após a queima possui consistência porosa e pode ser triturado a partir de pilão manual, não havendo necessidade do uso de trituradores elétricos ou combustão. Isto possibilita a utilização da cinza de osso por produtores com baixo capital de investimento.

No tocante à sanidade do material resultante, estudos sobre a degradação térmica da madeira relatam que a combustão da madeira apresenta quatro diferentes etapas, com variações de temperatura de $95-1.000^{\circ} \mathrm{C}$, quando o carvão é rapidamente consumido (Pinto \& Calil Júnior 2006). As altas temperaturas associadas à queima da madeira podem ser consideradas benéficas, quando contribuem para a eliminação de agentes infecciosos que possam estar associados às carcaças de ossos bovinos. Como exemplo, a Organização Mundial da Saúde considera a incineração de resíduos como um método efetivo na inativação do agente infeccioso das encefalopatias espongiformes transmissíveis, cujo agente infeccioso (o príon) é dos mais resistentes, sobrevivendo ao congelamento, ressecamento e calor do cozimento normal, da pasteurização e da esterilização à temperatura em tempo usual (Eduardo et al. 2008).

A legislação sobre orgânicos, no Brasil, permite o uso de cinza de osso para fertilização de solos, desde que o uso siga os parâmetros técnicos para se evitar impactos ambientais, e que o resíduo animal não seja oriundo de atividade ilegal (Brasil 2008). O maior entrave ao uso de cinza de osso em unidades de produção familiar encontra-se nas exigências mínimas de estrutura para processamento e transporte de resíduos animais, pois a normativa vigente (Brasil 1962) é focada em atividades de agroindústrias de maior porte.

\section{CONCLUSÃO}

A cinza de osso apresenta quantidade satisfatória de fósforo e cálcio e pode ser utilizada como adubo fosfatado e calcinado.

\section{REFERÊNCIAS}

ALBUQUERQUE, G. de A. S. C. de. A produção de fosfato no Brasil: uma apreciação histórica das condicionantes envolvidas. Rio de Janeiro: Cetem/CNPq, 1996. (Estudos e documentos, 31).

BRASIL. Decreto No 1.255, de 25 de junho de 1962. Aprova o Regulamento da Inspeção Industrial e Sanitária de Produtos de Origem Animal. Diário Oficial da República Federativa do Brasil, Poder Executivo, Brasília, DF, 4 jul. 1962. Seção 1, p. 7238.

BRASIL. Instrução Normativa $N^{\circ} 5$, de 23 de fevereiro de 2007. Aprova as definições e normas sobre as especificações e as garantias, a tolerância, o registro, a embalagem e a rotulagem dos fertilizantes minerais, 
destinados à agricultura. Diário Oficial da República Federativa do Brasil, Poder Executivo, Brasília, DF, 1 mar. 2007a. Seção 1, p. 10.

BRASIL. Instrução Normativa No 28 , de 27 de julho de 2007. Aprova os métodos analíticos oficiais para fertilizantes minerais, orgânicos, organo-minerais e corretivos, disponíveis na Coordenação-Geral de Apoio Laboratorial - CGAL/SDA/MAPA, na Biblioteca Nacional de Agricultura - BINAGRI e no sítio do Ministério da Agricultura, Pecuária e Abastecimento. Diário Oficial da República Federativa do Brasil, Poder Executivo, Brasília, DF, 31 jul. 2007b. Seção 1, p. 21.

BRASIL. Ministério da Agricultura, Pecuária e Abastecimento. Instrução Normativa No 64 , de 18 de dezembro de 2008. Aprova o Regulamento Técnico para os Sistemas Orgânicos de Produção Animal e Vegetal. Diário Oficial da República Federativa do Brasil, Poder Executivo, Brasília, DF, 19 dez. 2008. Seção 1, p. 21-26.

CAIONE, G. et al. Fontes de fósforo para adubação de cana-de-açúcar forrageira no Cerrado. Pesquisa Agropecuária Tropical, Goiânia, v. 41, n. 1, p. 66-73, 2011.

COSTA, M. S. S. de M. et al. Compostagem de resíduos sólidos de frigorífico. Revista Brasileira de Engenharia Agrícola e Ambiental, Campina Grande, v. 13, n. 1, p. 100107, 2009.

DIM, V. P. et al. Fertilidade do solo e produtividade de capim mombaça adubado com resíduos sólidos de frigorífico. Revista Brasileira de Saúde e Produção Animal, Salvador, v. 11, n. 2, p. 303-316, 2010.

EDUARDO, M. B. de P.; KATSUYA, E. M.; BASSIT, N. P. Vigilância da doença de Creutzfeldt-Jakob e outras doenças priônicas: normas e instruções. São Paulo: SESSP, 2008.

EMPRESA BRASILEIRA DE PESQUISA AGROPECUÁRIA (Embrapa). Centro Nacional de Pesquisa de Solos. Manual de métodos de análise de solos. 2. ed. Rio de Janeiro: Embrapa, 1997. (Documentos, 1).

FERREIRA, M. A.; CÓTICA, L. F.; MIYAHARA, R. Y. Estudo morfológico de hidroxiapatita obtida de cinza de ossos bovinos. In: SEMANA DE INTEGRAÇÃO ENSINO, PESQUISA E EXTENSÃO, 2009, Irati. Anais... Irati: Unicentro, 2009. Disponível em: $<\mathrm{http} / / /$ anais. unicentro.br/siepe/2009/pdf/resumo_609.pdf>. Acesso em: 20 ago. 2012.

GOUVÊA, D. et al. Efeito da temperatura de calcinação nas propriedades de ossos bovinos para a fabricação de porcelana de ossos. Cerâmica, São Paulo, n. 53, p. 423428, 2007.

INSTITUTE FOR PROSPECTIVE TECHNOLOGICAL STUDIES (IPTS). Joint Research Centre. Reference document on best available techniques in the slaughterhouses and animal by-products industries. Sevilha: EIPPCB, 2005.
JOHN, C. W. On the history of fertilizers. The Quarterly Journal of Agriculture, Edinburgh, v. 5, n. 1, p. 172-187, 1840.

MALAVOltA, E. $A B C$ da adubação. São Paulo: Agronômica Ceres. 1989.

MALAVOLTA, E.; PIMENTEL-GOMES, F.; ALCARDE, J. C. Adubos e adubações: adubos minerais e orgânicos. São Paulo: Nobel, 2002.

MAZOYER, M.; ROUDART, L. A mecanização do cultivo com tração animal e a revolução dos transportes. In: MAZOYER, M.; ROUDART, L. (Eds.). História das agriculturas no mundo: do neolítico à crise contemporânea. São Paulo: Unesp, 1933. p. 397-418.

MELO, W. J. et al. Experimentação sob condições controladas. Jaboticabal: Funep, 1998.

MIYAHARA, R. Y.; GOUVEA, D.; TOFFOLI, S. M. Obtenção e caracterização de cinza de ossos bovinos visando à fabricação de porcelana de ossos - bone China . Cerâmica, São Paulo, v. 53, n. 327, p. 234-239, 2007.

PACHECO, J. A. S.; WOLFF, D. B. Tratamento dos efluentes de um frigorífico por sistema australiano de lagos de estabilização. Disciplinarum Scientia, Santa Maria, v. 5, n. 1, p. 67-85, 2004.

PACHECO, J. W. Guia técnico ambiental de graxais. São Paulo: Cetesb, 2006.

PACHECO, J. W.; YAMANAKA, H. T. Guia técnico ambiental de abates (bovino e suíno). São Paulo: Cetesb, 2006.

PINTO, E. M.; CALIL JÚNIOR, C. Estudo teórico e experimental sobre a degradação térmica e os gradientes térmicos da madeira de Eucalyptus de uso estrutural exposta ao fogo. Revista Minerva: Pesquisa \& Tecnologia, São Carlos, v. 3, n. 2, p. 131-140, 2006.

RODRIGUES, A. C. et al. Produção e nutrição mineral do maracujazeiro-amarelo em solo com biofertilizante supermagro e potássio. Revista Brasileira de Engenharia Agrícola e Ambiental, Campina Grande, v. 13, n. 2, p. 117 124, 2009.

TSUYOSHI, K. et al. Measurement of pore structure of bone China body during a heating process by mercury intrusion porosimeter and SEM. Journal of the Ceramic Society of Japan, Tokyo, v. 107, n. 1245, p. 476-481, 1999.

TYPOGRAPHIA COMMERCIAL PORTUENSE (TCP). Sobre o emprego de ossos pizados na agricultura. In: TCP. O Museu Portuense. Porto: TCP, 1839. p. 45-47.

UNITED NATIONS INDUSTRIAL DEVELOPMENT ORGANIZATION (UNIDO). International Fertilizer Development Center. Status of the fertilizer industry. In: UNIDO (Ed.). Fertilizer manual. Dordrecht: Kluwer Academic Publishers, 1998. p. 45-69. 